\title{
Diagnostic Infectious Diseases Testing Outside Clinics: A Global Systematic Review and Meta-analysis
}

\begin{abstract}
Eneyi E. Kpokiri, ${ }^{1, a, \bullet}$ Gifty Marley, ${ }^{2, a}$ Weiming Tang, ${ }^{3,4, a}$ Noah Fongwen,, ${ }^{1}$ Dan Wu, ${ }^{1, \bullet}$ Sima Berendes, ${ }^{1}$ Bhavana Ambil, ${ }^{5}$ Sarah-Jane Loveday, ${ }^{6}$ Ranga Sampath, ${ }^{6}$ Jennifer S. Walker, ${ }^{7}$ Joseph K. B. Matovu, ${ }^{8}$ Catharina Boehme, ${ }^{6, b}$ Nitika Pant Pai, ${ }^{9,10, b}$ and Joseph D. Tucker,11,b

${ }^{1}$ Faculty of Infectious and Tropical Diseases, London School of Hygiene and Tropical Medicine, London, UK, ${ }^{2}$ School of Public Health, Nanjing Medical University, Jiangsu, China, ${ }^{3}$ Dermatology Hospital, Southern Medical University, Guangzhou, China, ${ }^{4}$ University of North Carolina at Chapel Hill, Project-China, Chapel Hill, North Carolina, USA, ${ }^{5}$ Department of Global Health, North Carolina State University, Raleigh, North Carolina, USA, ${ }^{6}$ Foundation for Innovative New Diagnostics, Switzerland, ${ }^{7}$ Health Sciences Library, University of North Carolina, Chapel Hill, North Carolina, USA, ${ }^{8}$ Makerere University School of Public Health, Kampala, Uganda, ${ }^{9}$ CORE, Research Institute of McGill University Health Centre, Montreal, Quebec, Canada, ${ }^{10}$ Division of Clinical Epidemiology \& Infectious Diseases, Department of Medicine, McGill University, Montreal, Quebec, Canada, and ${ }^{11}$ Institute of Global Health and Infectious Diseases, University of North Carolina, Chapel Hill, North Carolina, USA
\end{abstract}

Background. Most people around the world do not have access to facility-based diagnostic testing, and the gap in availability of diagnostic tests is a major public health challenge. Self-testing, self-sampling, and institutional testing outside conventional clinical settings are transforming infectious disease diagnostic testing in a wide range of low- and middle-income countries (LMICs). We examined the delivery models of infectious disease diagnostic testing outside clinics to assess the impact on test uptake and linkage to care.

Methods. We conducted a systematic review and meta-analysis, searching 6 databases and including original research manuscripts comparing testing outside clinics with conventional testing. The main outcomes were test uptake and linkage to care, delivery models, and adverse outcomes. Data from studies with similar interventions and outcomes within thematic areas of interest were pooled, and the quality of evidence was assessed using GRADE. This study was registered in PROSPERO (CRD42019140828).

We identified 10386 de-duplicated citations, and 76 studies were included. Data from 18 studies were pooled in meta-analyses. Studies focused on HIV (48 studies), chlamydia (8 studies), and multiple diseases (20 studies). HIV self-testing increased test uptake compared with facility-based testing (9 studies: pooled odds ratio [OR], 2.59; 95\% CI, 1.06-6.29; moderate quality). Self-sampling for sexually transmitted infections increased test uptake compared with facility-based testing (7 studies: pooled OR, 1.74; 95\% CI, 0.97-3.12; moderate quality).

Conclusions. Testing outside of clinics increased test uptake without significant adverse outcomes. These testing approaches provide an opportunity to expand access and empower patients. Further implementation research, scale-up of effective service delivery models, and policies in LMIC settings are needed.

Keywords. decentralized, HIV, infectious diseases, self-collection, self-testing, STD

Infectious disease diagnostics are not available to large numbers of people around the world, especially in low- and middleincome countries (LMICs) [1]. Diagnostic and screening tests are often confined to clinics with specialized laboratories [2-4]. Community clinics may not have the capacity to undertake diagnostic testing that requires special equipment and/or extensively trained personnel to perform tests $[4,5]$. Many people

\footnotetext{
Received 13 July 2020; editorial decision 5 August 2020; accepted 10 August 2020.

a'Equal contribution

${ }^{\mathrm{b}} \mathrm{Co}$-senior authors

Correspondence: Joseph D. Tucker, MD, PhD, AM, Institute of Global Health and Infectious Diseases, University of North Carolina, 130 Mason Farm Road, Bioinformatics Building, CB 7030, Chapel Hill, NC 27599-7030 (jdtucker@med.unc.edu).

Open Forum Infectious Diseases ${ }^{\circledR}$

(C) The Author(s) 2020. Published by Oxford University Press on behalf of Infectious Diseases Society of America. This is an Open Access article distributed under the terms of the Creative Commons Attribution-NonCommercial-NoDerivs licence (http://creativecommons.org/licenses/ by-nc-nd/4.0/), which permits non-commercial reproduction and distribution of the work, in any medium, provided the original work is not altered or transformed in any way, and that the work is properly cited. For commercial re-use, please contact journals.permissions@oup.com
} DOl: 10.1093/ofid/ofaa360 delay seeking care at centralized clinics because of stigma, competing demands, and transportation problems $[3,6,7]$.

Diagnostic services provided outside conventional settings could help to close this gap. Such services include self-testing, self-sampling, and institutional testing. Self-testing has an individual collect their own specimen and interpret the test result [8]. Self-sampling has an individual collect their own specimen but receive the result from a laboratory [9]. Institutional testing takes place in pharmacies, schools, correctional facilities, or other settings $[7,10,11]$. These new approaches are transforming the field of diagnostic testing by expanding access to testing, empowering individuals, and creating innovative testing models [12].

Previous reviews have mostly focused on self-testing for HIV and self-sampling for sexually transmitted infections (STIs) [13-16]. In addition, studies have not examined how these different diagnostic approaches are shifting power away from centralized testing and toward the patients themselves. Selftesting and self-sampling become particularly advantageous 
in lockdown situations with restricted movement, as seen in the COVID-19 outbreak, where access to health care services and diagnostic testing become limited to medical emergencies. Testing outside of clinics gives greater agency to people and provides an opportunity to develop different service delivery models. The purpose of this study was to examine infectious disease diagnostic testing outside of clinics using a systematic review and meta-analysis.

\section{METHODS}

We conducted a systematic review and meta-analysis to identify new models applied to decentralized infectious disease testing. The systematic review was reported using the Preferred Reporting Items for Systematic Reviews and Meta-Analyses (PRISMA) checklist (Supplementary File 1) and conducted following methodology described in the Cochrane handbook [17, 18]. We developed a protocol for the review (Supplementary File 2), and it was registered in PROSPERO before commencing the review (CRD42019140828).

\section{Search Strategy}

We searched 6 databases including PubMed, Embase, Scopus, Web of Science, Global Health, and CINAHL for relevant literature. Search terms were identified by health sciences librarians from the University of North Carolina with experience in search algorithms. Search terms used in the databases included MeSH terms, keywords, and free text (Supplementary File 3). The search was conducted on July 10, 2019, and updated on August 8, 2019. Our search was not restricted by the year of publication or geographical location. We searched reference lists of articles included for additional citations.

\section{Eligibility Criteria}

Original research that compared testing outside of a clinic with a laboratory vs conventional testing in clinics was included. All eligible studies were in the English language and were focused on self-testing, self-sampling, and/or institutional testing for infectious diseases. Studies that compared testing outcomes from interventions and conventional approaches regardless of study design were eligible for pooling. We included data from 14 different infections/infectious diseases including HIV, human papillomavirus (HPV), hepatitis B, hepatitis C, syphilis, chlamydia, tuberculosis, gonorrhea, filariasis, trachoma, leprosy, dengue, visceral leishmaniasis, and influenza. We excluded systematic reviews, conference abstracts, and studies that lacked a comparator group.

\section{Study Selection}

Citations were uploaded into Endnote and de-duplicated. Six reviewers were assigned individual sections for title screening. Next, the 6 reviewers independently assessed the included abstracts assigned to them for full-text reviews. Full-text studies were evaluated by 2 independent individuals for eligibility and inclusion. Studies with disagreements were sent to a third reviewer and discussed among the group, and a decision was reached to either include or exclude the study.

\section{Data Extraction}

We extracted data based on our prespecified outcomes of interest. Data extracted included study design and location, testing site, type of test (self-testing, self-sampling), disease, sample size, linkage to care, test uptake, target population, test payment (out-of-pocket, paid for by research study, etc.), cost-effectiveness, and adverse outcomes reported. We defined linkage to care in HIV and all disease as any follow-up or contact with health care professionals including treatment initiation within 6 months of testing.

\section{Quality Assessment for Included Studies}

The quality of studies included for data pooling was assessed using the GRADE approach methodology [19]. For each study, we examined study limitations, risk of bias, consistency, precision, and other factors. The overall findings were assessed as high, moderate, low, or very low.

\section{Analysis of Key Outcomes}

Data from studies with the prespecified interventions of interest and outcomes with a comparator arm were pooled and analyzed. Studies that fit within thematic areas of interest, had a comparator arm that evaluated out-of-clinic with laboratory testing vs conventional facility testing, and had complete data (on number of participants recruited and number of participants tested) for both comparator arms were eligible for inclusion in the metaanalyses. Meta-analyses of prespecified groups were performed according to the different intervention approaches and outcomes of interest, and unadjusted odds ratios were calculated using Review Manager 5.3. Heterogeneity was assessed with an $I^{2}$ statistic [20]. We used a random-effects model in this study to ensure that variance was not underestimated.

\section{RESULTS}

The database search identified 21344 citations, of which 10958 were nonduplicates. A total of 76 studies were included in the systematic review (Figure 1; Supplementary File 4). Of the 76 studies, 18 studies were eligible for meta-analysis based on our thematic areas of interest and were pooled. The database search strategy identified 72 studies, and 4 additional studies were identified by hand searching of reference lists. We identified 46 randomized controlled trials and 30 observational studies. Studies focused on HIV (48 studies), chlamydia (8 studies), gonorrhea (11 studies), syphilis (4 studies), HPV (2 studies), hepatitis (3 studies), and tuberculosis (2 studies). Twenty studies focused on multiple diseases. Twenty-four studies included sexual minorities, 13 studies included testers in remote locations, and

2 - OFID - Kpokiri et al 


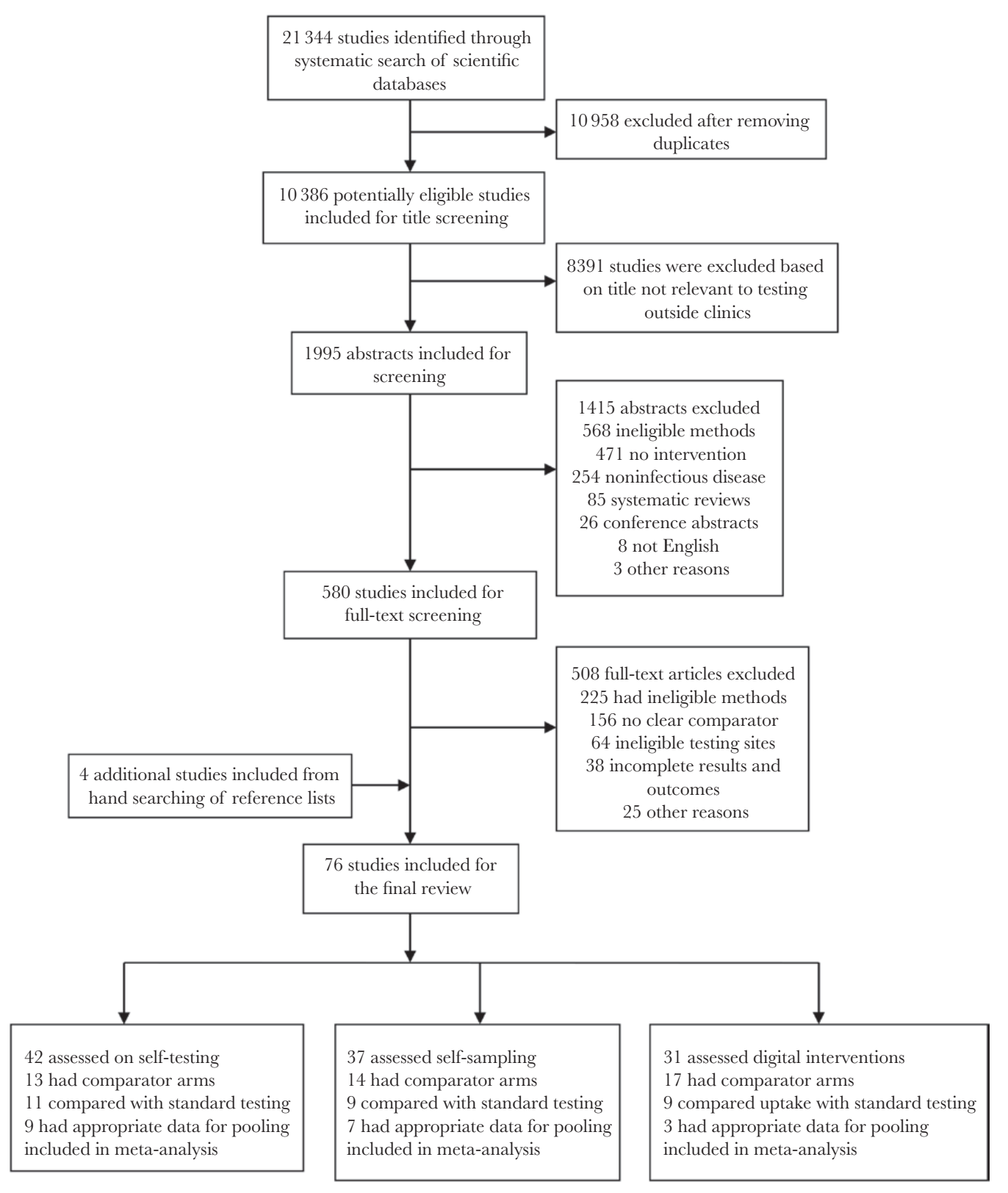

Figure 1. Study selection.

6 studies included first-time testers (Table 1). More than half $(55 \%)$ of these studies were conducted in LMICs $(n=42)$, and $45 \%(\mathrm{n}=34)$ were in high-income countries. We observed that testing outside of clinics created new delivery approaches, increased test uptake, empowered testers, and had minimal risks.

HIV self-testing increased test uptake compared with facility-based testing ( 9 studies in 5 countries: pooled odds ratio [OR], 2.59; 95\% CI, 1.06-6.29; $I^{2}=99 \% ; \mathrm{n}=33912$ ) (Table 2, Figure 2) [21-30]. The overall certainty of the evidence was moderate (Supplementary File 5). Self-sampling for STIs (HIV, chlamydia, gonorrhea, hepatitis, and syphilis), which involved collecting body samples and submitting to a facility for testing, increased test uptake compared with facility-based diagnostic testing (7 studies in 5 countries: OR, 1.74; 95\% CI, 0.97-3.12; $I^{2}=95 \%$; $\mathrm{n}=14256$; moderatequality evidence) (Figure 3) [31-35]. Testing outside clinics nonsignificantly increased access to diagnostic testing among sexual minorities and people in remote regions when compared with testing in conventional settings (OR, 1.16; 95\% CI, $0.88-1.53 ; I^{2}=93 \% ; \mathrm{n}=2525$ ) [35-41]. Four studies in LMICs reported a higher rate of testing in first-time testers among those who participated in testing models outside clinics 


\begin{tabular}{|c|c|}
\hline Characteristic & No. of Studies \\
\hline Self-testing & 10 (7 LMICs; 3 HICs) \\
\hline HIV & 10 \\
\hline Other STIs & 0 \\
\hline Self-sampling & 6 (2 LMICs; 4 HICs) \\
\hline Non-HIV STIs & 5 \\
\hline Multiple STIs & 1 \\
\hline Digital technology approach & 6 (4 LMICs; 2 HICs) \\
\hline HIV & 6 \\
\hline Non-HIV & 0 \\
\hline Multiple STIs & 0 \\
\hline \multicolumn{2}{|l|}{ Study design } \\
\hline RCT & 46 (26 LMICs; 20 HICs) \\
\hline Observational & 30 (14 LMICs; 16 HICs) \\
\hline \multicolumn{2}{|l|}{ Infectious disease } \\
\hline HIV & 48 (36 LMICs; 12 HICs) \\
\hline Chlamydia & $8(8 \mathrm{HICs})$ \\
\hline Multiple diseases & 20 (6 LMICs; 14 HICs) \\
\hline \multicolumn{2}{|l|}{ Population type } \\
\hline Sexual minorities & 24 (12 LMICs; 12 HICs) \\
\hline First-time testers & 6 (4 LMICs; 2 HICs) \\
\hline
\end{tabular}

compared with conventional testing [21, 39, 42, 43]. Linkage to care was evaluated in 13 studies (Table 3), most of which were HIV-focused (10 studies, 8 in LMICs). The mean linkage to care rate for HIV within 6 months of testing was $17.3 \%$ in the testing-outside-of-clinics groups compared with $16.5 \%$ in the facility-based arms.

Testing outside of clinics gives power to all self-testers and self-sample testers (people receiving testing) about when, where, and how to test. One study showed that testing outside of clinics allowed for testing during the evenings, weekends, or holidays [44]. These approaches also allowed testers to test at home, at work, or at another location of their own choosing (3 studies in 3 countries) $[26,35,45]$. Testing outside of clinics allowed testers to give test kits to friends (1 study in 1 country) [22] and refer a partner (spouses and/or sex partners; 7 studies in 4 countries) [21, 24, 30, 46-48].

Innovative test delivery services (through mail services, online, pharmacies, schools, or correctional settings) improved test uptake compared with facility-based testing services. Fourteen studies that used local postal systems to mail an entire test kit (self-testing) or specimen collection kit (self-sampling) to the tester showed an increase in testing rates (OR, 1.41; 95\% CI, $\left.1.12-1.78 ; I^{2}=92 \% ; \mathrm{n}=1603\right)[33,34,36,46,49,50]$. Five studies in 4 countries used pharmacies to distribute test-based services (OR, 2.47; 95\% CI, 1.85-3.30; $I^{2}=94 \%$; $=1393$ ) [48, 51-54]. Three studies in 2 countries used schools or other educational settings to distribute diagnostic services (OR, 1.19; 95\% CI, 0.68-2.06; $I^{2}=92 \% ; \mathrm{n}=203$ ) [55-57]. Overall, 10 studies used digital interventions to enhance test uptake (Table 4). We 


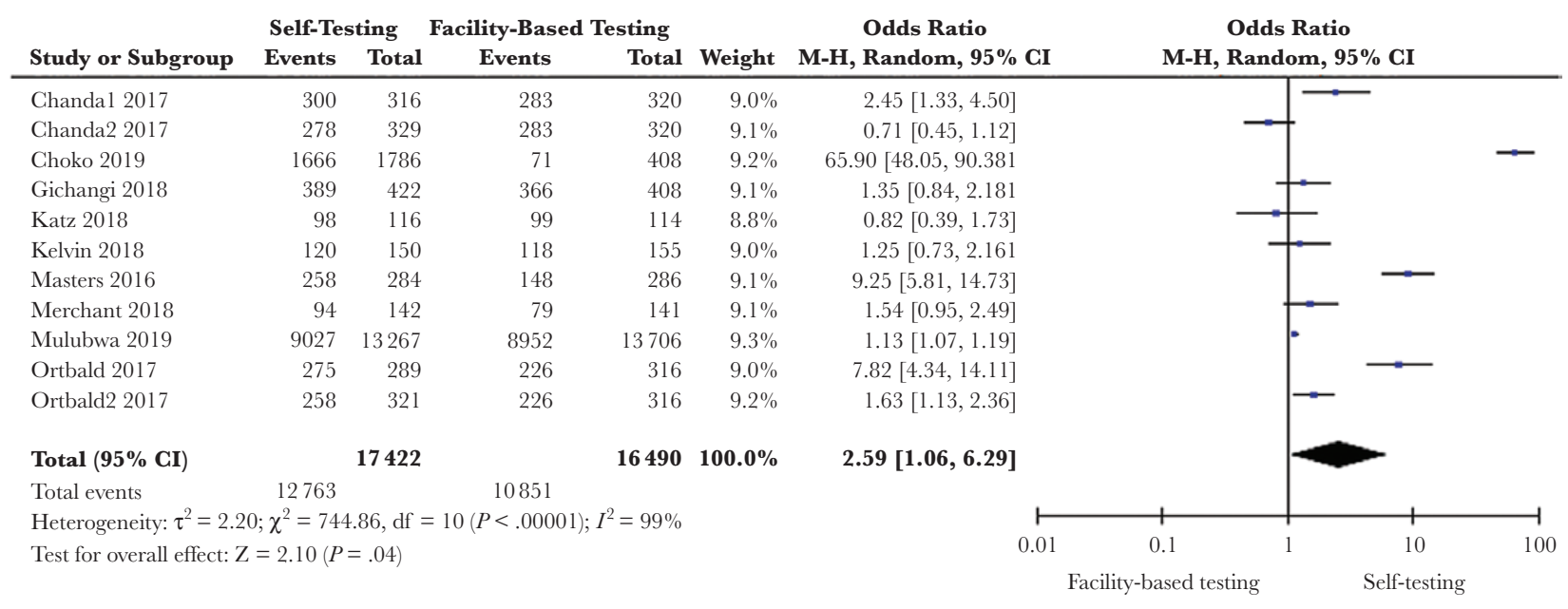

Figure 2. Self-testing compared with facility-based testing.

defined digital as emails, websites, instant messaging, or related internet approaches. Seven studies found that digital interventions increased the number of people who request diagnostic tests for infectious diseases compared with conventional approaches. Three additional studies evaluated the effect of digital interventions in improving STI self-sampling compared with conventional approaches, with a pooled OR of 3.50 (95\% CI, $1.35-9.08 ; I^{2}=99 \% ; \mathrm{n}=31241$; low quality of evidence) (Figure 4).

In terms of adverse outcomes, 3 studies examined the risks associated with testing outside of clinics. These articles reported on intimate partner violence, coercive testing, and depression and self-harm $[24,52,58]$. The rate of adverse events associated with testing outside clinics was found to be low $(0.003 \%$ of participants in 2 studies), which was similar to adverse events in facility-based testing. Eight studies in 5 countries examined the cost associated with testing outside of clinics. Three out of 4 studies assessing cost-effectiveness found that testing outside of clinics was cost-effective compared with facility-based approaches [59-61].

\section{DISCUSSION}

Our systematic review found that testing outside of clinics increased diagnostic test access compared with conventional testing. The risks of adverse events associated with testing outside the facility compared with facility-based testing are minimal. HIV self-testing digital interventions increased diagnostic test uptake, and the linkage to care rate was similar compared with conventional approaches. This study expands the literature by summarizing the use of decentralized diagnostic testing for multiple infectious diseases, examining service delivery models not covered in previous reviews, and evaluating linkage to care for diagnostic testing outside conventional settings.

We found that STI self-sampling increased test uptake compared with conventional testing approaches [31-35]. This is

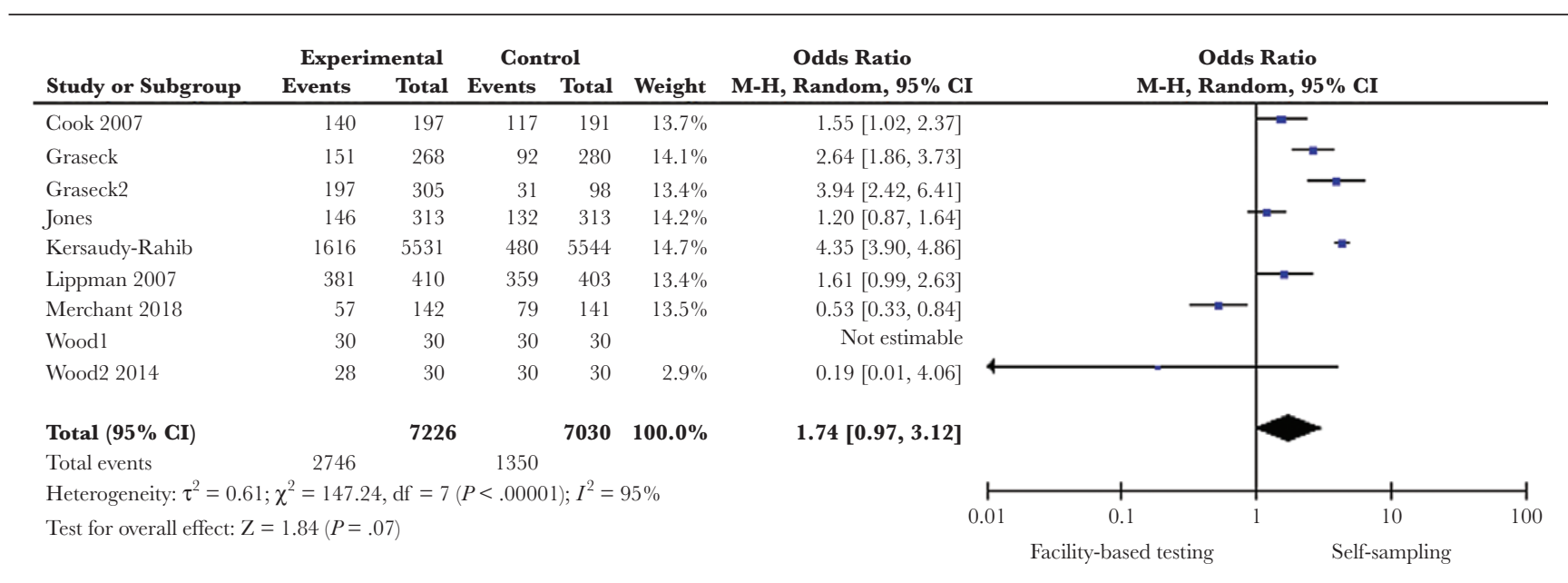

Figure 3. Sexually transmitted infection self-sampling compared with facility-based testing. 


\begin{tabular}{|c|c|c|c|c|c|}
\hline Study & Location & Target Population & Disease & $\begin{array}{l}\text { \% Linked to Care } \\
\text { (Intervention vs Control Group) }\end{array}$ & $\begin{array}{c}\text { Linkage to Care } \\
\text { Time Point }\end{array}$ \\
\hline MacPherson et al. 2014 [29] & Malawi & Adults & HIV & $2.2 \%$ vs $0.7 \%$ & $6 \mathrm{mo}$ \\
\hline Morano et al. 2014 [84] & USA & General population & $\mathrm{HCV}$ & $93.8 \%$ vs $18.2 \%$ & $1 \mathrm{mo}$ \\
\hline Parker et al. 2015 [85] & Swaziland & General population & HIV & $34.0 \%$ vs N/A & $6 \mathrm{mo}$ \\
\hline Kelvin et al. 2019 [43] & Kenya & Female sex workers & HIV & $14.0 \%$ vs $9.3 \%$ & $2 \mathrm{mo}$ \\
\hline Chanda et al. 2017 [52] & Zambia & Female sex workers & HIV & $51.9 \%$ vs $61.1 \%$ & $4 \mathrm{mo}$ \\
\hline Reddy et al. 2016 [73] & USA & MSM & HIV & $73 \%$ vs N/A & $6 \mathrm{mo}$ \\
\hline Meehan et al. 2017 [61] & USA & University students & Chlamydia & $74 \%$ vs $50 \%$ & Not stated \\
\hline Miller et al. 2017 [82] & France & $\begin{array}{l}\text { Young adults } \\
\text { (aged 17-24 y) }\end{array}$ & HIV & $85.1 \%$ vs $35.1 \%$ & Not stated \\
\hline Barnabas et al. 2016 [70] & S/A Uganda & $\begin{array}{l}\text { Men } \\
\text { (aged 16-49 y) }\end{array}$ & HIV & $74 \%$ vs $66 \%$ & $9 \mathrm{mo}$ \\
\hline Ortblad et al. 2017 [23] & Uganda & Female sex workers & HIV & $8.3 \%$ vs $8.2 \%$ & $4 \mathrm{mo}$ \\
\hline Choko et al. 2019 [21] & Malawi & Pregnant women & HIV & $10 \%$ vs $4 \%$ & $1 \mathrm{mo}$ \\
\hline Green et al. 2018 [39] & Vietnam & MSM & HIV & $81 \%$ vs $69.1 \%$ & Not stated \\
\hline Johnston et al. 2018 [86] & Canada & General population & HIV & $63.2 \%$ vs $29.3 \%$ & Not stated \\
\hline
\end{tabular}

Abbreviation: MSM, men who have sex with men.

consistent with a global literature suggesting patient preference for self-sampling [62-64]. Self-sampling kits require minimal technical skills, may be cost-effective, and diversify testing locations $[65,66]$. Self-sampling could enhance early detection of many STIs for which self-testing is not available $[67,68]$. This approach could simplify and streamline the process of diagnostic testing [69].

We found that HIV self-testing digital interventions increased testing rates compared with conventional approaches in 6 studies [25, 38, 43, 70-72]. This finding is consistent with earlier literature on promoting HIV self-testing $[33,73]$ but to our knowledge has not been the focus of previous systematic review findings. This finding is consistent with earlier studies that report that advertising free HIV self-testing kits on dating websites, mobile phone apps, and social media platforms helped to reach more men who have sex with men (MSM). This also simplified and increased access to many first-time testers when compared with testing in conventional health facilities [74-76].
Although digital interventions may be preferred by some key populations, this approach relies on self-reporting results, which may reduce the validity of the findings $[77,78]$. However, external validation can be obtained through built-in interpretation programs to reduce bias due to self-reporting of test results. It is therefore important for digital self-testing strategies and models to incorporate linkage-to-care services such as real-time online supervised testing, digital tracking of test kit utilization, and provider-initiated follow-up calls or other interventions $[21,79,80]$.

We observed a similar rate of linkage to HIV care after testing outside of clinics compared with conventional facility-based testing. This finding may be a result of who chooses to test outside of clinics and is similar to an observation made in a Copenhagen study [81], but has not been the focus of systematic reviews. Although other research has shown lower linkage to HIV care following self-testing $[23,29,39,82]$, recent studies suggest that embedding HIV self-testing with health provider-initiated

Table 4. Use of Digital Technology Across the Testing Continuum

\begin{tabular}{|c|c|c|c|c|}
\hline \multicolumn{5}{|c|}{ Digital Technology Across the Testing Continuum } \\
\hline Digital Technology & $\begin{array}{l}\text { Promote Testing } \\
\text { (Demand Generation) }\end{array}$ & $\begin{array}{l}\text { Focus Testing Services } \\
\text { (who Should Be Tested) }\end{array}$ & $\begin{array}{l}\text { Order and Receive } \\
\text { Self-Testing or } \\
\text { Self-Sampling Kit }\end{array}$ & $\begin{array}{c}\text { Results Notification/ } \\
\text { Instructions and Counseling }\end{array}$ \\
\hline Websites, email & $\begin{array}{l}\text { Katz } 2018 \text { [25] } \\
\text { Kersaudy-Rahib } 2017 \text { [33] } \\
\text { Jenkins } 2012 \text { [55] }\end{array}$ & Jenkins 2012 [55] & Jenkins 2012 [55] & Wang 2018 [71] \\
\hline Social media & Katz 2018 [25] & & & \\
\hline Mobile apps & $\begin{array}{l}\text { Wray } 2018 \text { [38] } \\
\text { Zhu } 2019 \text { [72] }\end{array}$ & & & \\
\hline Text messages & $\begin{array}{l}\text { Barnabas } 2016 \text { [70] } \\
\text { Kelvin } 2018 \text { [26] } \\
\text { Kelvin } 2019 \text { [43] }\end{array}$ & $\begin{array}{l}\text { Kelvin } 2018 \text { [26] } \\
\text { Kelvin } 2019 \text { [43] }\end{array}$ & & Barnabas 2016 [70] \\
\hline Remote monitoring sensors & Wray 2018 [38] & & & Wray 2018 [38] \\
\hline
\end{tabular}




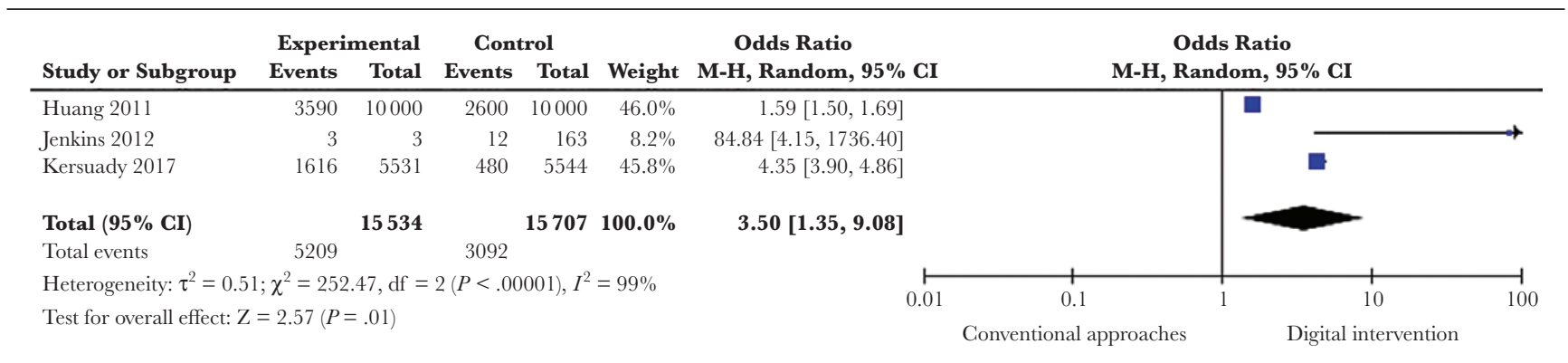

Figure 4. Use of digital interventions to promote infectious disease testing.

follow-up can enhance linkage to care [83]. There is still a need to improve linkage to HIV care after self-testing.

Our study has several important implications. From the policy viewpoint, this work demonstrates that the use of digital technology in testing outside clinics is a useful strategy for improving infectious diseases screening and linkage to care, and policies that aim to promote the use of these strategies are needed. These models may be especially useful for diseases associated with stigmatization such as HIV and other STIs, but many studies focus on HIV. Also, testing outside clinics will be a key strategy for continued testing in future pandemic situations where lockdowns and restricted movements are implemented. There is a need for more studies on the implementation of these strategies for other infectious diseases apart from STIs. Second, from the research perspective, we found that studies that aimed to evaluate the cost-effectiveness of decentralized diagnostic testing are limited, with most of these focusing on HIV infection alone. Future studies are needed to evaluate the cost-effectiveness, barriers, and facilitators of these approaches.

This study also has some limitations. First, very few studies have examined the risks and adverse outcomes associated with testing outside of clinics $[24,52,58]$. Further post-trial research is needed to fully understand the risks associated with testing outside of clinics. Second, none of the included studies provided testing to persons living with disabilities. This is another opportunity for expanding the impact of testing outside of clinics. Third, the number of studies for each outcome included in this study was low, and we noted that substantial heterogeneity across studies exists. Fourth, we only pooled the unadjusted results of the included studies, which may make the results biased. However, in most included studies, the participants in the conventional service group and the decentralized diagnostic testing group were reported to be comparable. Additionally, for studies that had multiple intervention arms compared with 1 control group, variance may have been underestimated.

\section{CONCLUSIONS}

Testing outside of clinics provides an opportunity to expand access to diagnostic testing for infectious diseases and give power to testers through innovative delivery models. Testing outside of clinics can reach the last mile of many health systems, driving access for hard-to-reach groups in diverse LMIC settings. The modest evidence on adverse events suggests that these occur at a similar rate in facility-based testing. Further implementation research and scale-up of effective decentralized models in LMIC settings are needed.

\section{Supplementary Data}

Supplementary materials are available at Open Forum Infectious Diseases online. Consisting of data provided by the authors to benefit the reader, the posted materials are not copyedited and are the sole responsibility of the authors, so questions or comments should be addressed to the corresponding author.

\section{Acknowledgments}

Financial support. This work was supported by the Foundation for Innovative New Diagnostics (FIND) and NIH grants: NIAID K24AI143471, NICHD UG3HD096929.

Potential conflicts of interest. All authors: no reported conflicts of interest. All authors have submitted the ICMJE Form for Disclosure of Potential Conflicts of Interest. Conflicts that the editors consider relevant to the content of the manuscript have been disclosed.

Author contributions. C.B. and J.T. developed the original idea for this study. E.K., G.M., W.T., N.F., D.W., and S.B. conducted the literature screening. J.S.W. did the literature search, and J.D.T., N.P.P., C.B., S.J.L., and R.S. were responsible for the study design. E.K., G.M., N.F., D.W., and S.B. did the data extraction, and W.T. did the analysis and created figures. E.K. and J.D.T. wrote the first draft of the manuscript. E.K., G.M., W.T., and J.D.T. wrote the report, and all authors reviewed and approved the final version.

Patient consent. This study only included a secondary data analysis and, as a result, did not require patient consent.

\section{References}

1. Wilson ML, Atun R, DeStigter K, et al; Commissioners of The Lancet Commission on Diagnostics. The Lancet Commission on Diagnostics: advancing equitable access to diagnostics. Lancet 2019; 393:2018-20.

2. Ngo A, Gandhi P, Miller WG. Frequency that laboratory tests influence medical decisions. J Appl Lab Med 2017; 1:410-4.

3. Engel N, Wachter K, Pai M, et al. Addressing the challenges of diagnostics demand and supply: insights from an online global health discussion platform. BMJ Glob Health 2016; 1:e00132.

4. Kuupiel D, Adu KM, Bawontuo V, Mashamba-Thompson TP. Geographical accessibility to district hospitals/medical laboratories for comprehensive antenatal point-of-care diagnostic services in the Upper East Region, Ghana. EClinicalMedicine 2019; 13:74-80.

5. Mashamba-Thompson TP, Sartorius B, Drain PK. Operational assessment of point-of-care diagnostics in rural primary healthcare clinics of KwaZulu-Natal, South Africa: a cross-sectional survey. BMC Health Serv Res 2018; 18:380.

6. Yellapa V, Devadasan N, Krumeich A, et al. How patients navigate the diagnostic ecosystem in a fragmented health system: a qualitative study from India. Glob Health Action 2017; 10:1350452. 
7. Sutton M, Anthony MN, Vila C, et al. HIV testing and HIV/AIDS treatment services in rural counties in 10 southern states: service provider perspectives. J Rural Health 2010; 26:240-7.

8. World Health Organization. Guidelines on HIV Self-Testing and Partner Notification: Supplement to Consolidated Guidelines on HIV Testing Services. Geneva: World Health Organization; 2016.

9. Harding-Esch EM, Hollis E, Mohammed H, Saunders JM. Self-sampling and selftesting for STIs and HIV: the case for consistent nomenclature. Sex Transm Infect 2017; 93:445-8.

10. Hector J, Davies MA, Dekker-Boersema J, et al. Acceptability and performance of a directly assisted oral HIV self-testing intervention in adolescents in rural Mozambique. PLoS One 2018; 13:e0195391.

11. Holland-Hall CM, Wiesenfeld HC, Murray PJ. Self-collected vaginal swabs for the detection of multiple sexually transmitted infections in adolescent girls. J Pediatr Adolesc Gynecol 2002; 15:307-13.

12. Vojnov L, Taegtmeyer M, Boeke C, et al. Performance of non-laboratory staff for diagnostic testing and specimen collection in HIV programs: a systematic review and meta-analysis. PLoS One 2019; 14:e0216277.

13. Pai NP, Tulsky JP, Cohan D, et al. Rapid point-of-care HIV testing in pregnan women: a systematic review and meta-analysis. Trop Med Int Health 2007; 12:162-73.

14. Pedrana A, Stoove M, Bowring A, et al. P5-S7.16 Easy access "community-based HIV testing services for gay men: a systematic review." Sex Transm Infect 2011; 87(Suppl 1):A348-9.

15. Sharma M, Ying R, Tarr G, Barnabas R. Systematic review and meta-analysis of community and facility-based HIV testing to address linkage to care gaps in sub-Saharan Africa. Nature 2015; 528:S77-85

16. Paschen-Wolff MM, Restar A, Gandhi AD, et al. A systematic review of interventions that promote frequent HIV testing. AIDS Behav 2019; 23:860-74.

17. Moher D, Liberati A, Tetzlaff J, Altman DG; PRISMA Group. Preferred Reporting Items for Systematic Reviews and Meta-Analyses: the PRISMA statement. Ann Intern Med 2009; 151:264-9, W64.

18. Higgins JPT, Thomas J, Chandler J, et al. Cochrane Handbook for Systematic Reviews of Interventions Version 6.0 (Updated July 2019). 2019.

19. Guyatt GH, Oxman AD, Vist GE, et al; GRADE Working Group. GRADE: an emerging consensus on rating quality of evidence and strength of recommendations. BMJ 2008; 336:924-6.

20. Higgins JP, Thompson SG. Quantifying heterogeneity in a meta-analysis. Stat Med 2002; 21:1539-58.

21. Choko AT, Corbett EL, Stallard N, et al. HIV self-testing alone or with additional interventions, including financial incentives, and linkage to care or prevention among male partners of antenatal care clinic attendees in Malawi: an adaptive multi-arm, multi-stage cluster randomised trial. PLoS Med 2019; 16:e1002719.

22. Lightfoot MA, Campbell CK, Moss N, et al. Using a social network strategy to distribute HIV self-test kits to African American and Latino MSM. J Acquir Immune Defic Syndr 2018; 79:38-45.

23. Ortblad K, Kibuuka Musoke D, Ngabirano T, et al. Direct provision versus facility collection of HIV self-tests among female sex workers in Uganda: a clusterrandomized controlled health systems trial. PLoS Med 2017; 14:e1002458.

24. Masters SH, Agot K, Obonyo B, et al. Promoting partner testing and couples testing through secondary distribution of HIV self-tests: a randomized clinical trial. PLoS Med 2016; 13:e1002166.

25. Katz DA, Golden MR, Hughes JP, et al. HIV self-testing increases HIV testing frequency in high-risk men who have sex with men: a randomized controlled trial. J Acquir Immune Defic Syndr 2018; 78:505-12.

26. Kelvin EA, George G, Mwai E, et al. Offering self-administered oral HIV testing to truck drivers in Kenya to increase testing: a randomized controlled trial. AIDS Care 2018; 30:47-55

27. Merchant RC, Clark MA, Liu T, et al. Comparison of home-based oral fluid rapid HIV self-testing versus mail-in blood sample collection or medical/community HIV testing by young adult Black, Hispanic, and White MSM: results from a randomized trial. AIDS Behav 2018; 22:337-46.

28. Mulubwa C, Hensen B, Phiri MM, et al; HPTN 071 (PopART) Study Team. Community based distribution of oral HIV self-testing kits in Zambia: a clusterrandomised trial nested in four HPTN 071 (PopART) intervention communities. Lancet HIV 2019; 6:e81-92.

29. MacPherson P, Lalloo DG, Webb EL, et al. Effect of optional home initiation of HIV care following HIV self-testing on antiretroviral therapy initiation among adults in Malawi: a randomized clinical trial. JAMA 2014; 312:372-9.

30. Gichangi A, Wambua J, Mutwiwa S, et al. Impact of HIV self-test distribution to male partners of ANC clients: results of a randomized controlled trial in Kenya. J Acquir Immune Defic Syndr 2018; 79:467-73.

31. Graseck AS, Secura GM, Allsworth JE, et al. Home compared with clinic-based screening for sexually transmitted infections: a randomized controlled trial. Obstet Gynecol 2010; 116:1311-8.
32. Jones HE, Altini L, de Kock A, et al. Home-based versus clinic-based self-sampling and testing for sexually transmitted infections in Gugulethu, South Africa: randomised controlled trial. Sex Transm Infect 2007; 83:552-7.

33. Kersaudy-Rahib D, Lydié N, Leroy C, et al. Chlamyweb study II: a randomised controlled trial (RCT) of an online offer of home-based Chlamydia trachomatis sampling in France. Sex Transm Infect 2017; 93:188-95.

34. Lippman SA, Jones HE, Luppi CG, et al. Home-based self-sampling and selftesting for sexually transmitted infections: acceptable and feasible alternatives to provider-based screening in low-income women in São Paulo, Brazil. Sex Transm Dis 2007; 34:421-8.

35. Wood M, Ellks R, Grobicki M. Outreach sexual infection screening and postal tests in men who have sex with men: are they comparable to clinic screening? Int J STD AIDS 2015; 26:428-31.

36. Chin-Hong PV, Berry JM, Cheng SC, et al. Comparison of patient- and cliniciancollected anal cytology samples to screen for human papillomavirus-associated anal intraepithelial neoplasia in men who have sex with men. Ann Intern Med 2008; $149: 300-6$

37. Fisher M, Wayal S, Smith H, et al; Brighton Home Sampling Kit Project Steering Group. Home sampling for sexually transmitted infections and HIV in men who have sex with men: a prospective observational study. PLoS One 2015; 10:e0120810.

38. Wray TB, Chan PA, Simpanen E, Operario D. A pilot, randomized controlled trial of HIV self-testing and real-time post-test counseling/referral on screening and preventative care among men who have sex with men. AIDS Patient Care STDS 2018; 32:360-7.

39. Green KE, Vu BN, Phan HT, et al. From conventional to disruptive: upturning the HIV testing status quo among men who have sex with men in Vietnam. J In AIDS Soc 2018; 21(Suppl 5):e25127.

40. Ortblad KF, Kibuuka Musoke D, Ngabirano T, et al. The effect of HIV self-testing delivery models on female sex workers' sexual behaviors: a randomized controlled trial in Urban Uganda. AIDS Behav 2019; 23:1225-39.

41. Jamil MS, Prestage G, Fairley CK, et al. Effect of availability of HIV self-testing on HIV testing frequency in gay and bisexual men at high risk of infection (FORTH) a waiting-list randomised controlled trial. Lancet HIV 2017; 4:e241-50.

42. Kadede K, Ruel T, Kabami J, et al; SEARCH team. Increased adolescen HIV testing with a hybrid mobile strategy in Uganda and Kenya. AIDS 2016; 30:2121-6

43. Kelvin EA, George G, Kinyanjui S, et al. Announcing the availability of oral HIV self-test kits via text message to increase HIV testing among hard-to-reach truckers in Kenya: a randomized controlled trial. BMC Public Health 2019; 19:7.

44. Muhula S, Memiah P, Mbau L, et al. Uptake and linkage into care over one year of providing HIV testing and counselling through community and health facility testing modalities in urban informal settlement of Kibera, Nairobi Kenya. BMC Public Health 2016; 16:373.

45. Harichund C, Karim QA, Kunene P, et al. HIV self-testing as part of a differentiated HIV testing approach: exploring urban and rural adult experiences from KwaZulu-Natal, South Africa using a cross-over study design. BMC Public Health 2019; $19: 53$.

46. Falk L, Hegic S, Wilson D, Wiréhn AB. Home-sampling as a tool in the context of Chlamydia trachomatis partner notification: a randomized controlled trial. Acta Derm Venereol 2014; 94:72-4

47. Thirumurthy H, Masters S, Obonyo B, et al. Promoting male partner and couples HIV testing through secondary distribution HIV self-tests: a randomized trial. J Int AIDS Soc 2016; 19.

48. Oldenburg CE, Chanda MM, Ortblad KF, et al. Effect of HIV self-testing on the number of sexual partners among female sex workers in Zambia. AIDS 2018 32:645-52.

49. Cook RL, Østergaard L, Hillier SL, et al; DAISY study team. Home screening for sexually transmitted diseases in high-risk young women: randomised controlled trial. Sex Transm Infect 2007; 83:286-91.

50. Domeika M, Drulyte O. Use of PCR for the detection of genital Chlamydia trachomatis infection on self-obtained mailed vaginal samples. Acta Obstet Gynecol Scand 2000; 79:570-5.

51. Banerjee P, Thorley N, Radcliffe K. A service evaluation comparing home-based testing to clinic-based testing for chlamydia and gonorrhoea in Birmingham and Solihull. Int J STD AIDS 2018; 29:974-9.

52. Chanda MM, Ortblad KF, Mwale M, et al. HIV self-testing among female sex workers in Zambia: a cluster randomized controlled trial. PLoS Med 2017; 14:e1002442.

53. Crawford ND, Dean T, Rivera AV, et al. Pharmacy intervention to improve HIV testing uptake using a comprehensive health screening approach. Public Health Rep 2016; 131(Suppl 1):139-46.

54. Weidle PJ, Lecher S, Botts LW, et al. HIV testing in community pharmacies and retail clinics: a model to expand access to screening for HIV infection. J Am Pharm Assoc (2003) 2014; 54:486-92. 
55. Jenkins WD, Weis $\mathrm{R}$, Campbell $\mathrm{P}$, et al. Comparative effectiveness of two self-collected sample kit distribution systems for chlamydia screening on a university campus. Sex Transm Infect 2012; 88:363-7.

56. Bassett IV, Regan S, Mbonambi H, et al. Finding HIV in hard to reach populations: mobile HIV testing and geospatial mapping in Umlazi township, Durban, South Africa. AIDS Behav 2015; 19:1888-95.

57. Lebina L, Seatlholo N, Taruberekera N, et al. Feasibility of community-based HIV self-screening in South Africa: a demonstration project. BMC Public Health 2019; 19:898.

58. Des Marais AC, Zhao Y, Hobbs MM, et al. Home self-collection by mail to test for human papillomavirus and sexually transmitted infections. Obstet Gynecol 2018 132:1412-20.

59. Smith KJ, Cook RL, Ness RB. Cost comparisons between home- and clinic-based testing for sexually transmitted diseases in high-risk young women. Infect Dis Obstet Gynecol 2007; 2007:62467.

60. Maheswaran H, Petrou S, MacPherson P, et al. Cost and quality of life analysis of HIV self-testing and facility-based HIV testing and counselling in Blantyre, Malawi. BMC Med 2016; 14:34.

61. Meehan SA, Beyers N, Burger R. Cost analysis of two community-based HIV testing service modalities led by a non-governmental organization in Cape Town, South Africa. BMC Health Serv Res 2017; 17:801.

62. Paudyal P, Llewellyn C, Lau J, et al. Obtaining self-samples to diagnose curable sexually transmitted infections: a systematic review of patients' experiences. PLoS One 2015; 10:e124310.

63. Krause J, Subklew-Sehume F, Kenyon C, Colebunders R. Acceptability of HIV self-testing: a systematic literature review. BMC Public Health 2013; 13:735.

64. Wulandari LPL, Ruddick A, Guy R, Kaldor J. "Self-testing sounds more private, rather than going to the clinic and everybody will find out": facilitators and barriers regarding HIV testing among men who purchase sex in Bali, Indonesia. PLoS One 2019; 14:e0214987.

65. Polman NJ, Ebisch RMF, Heideman DAM, et al. Performance of human papillomavirus testing on self-collected versus clinician-collected samples for the detection of cervical intraepithelial neoplasia of grade 2 or worse: a randomised, paired screen-positive, non-inferiority trial. Lancet Oncol 2019; 20:229-38.

66. Petignat P, Faltin DL, Bruchim I, et al. Are self-collected samples comparable to physician-collected cervical specimens for human papillomavirus DNA testing? A systematic review and meta-analysis. Gynecol Oncol 2007; 105:530-5.

67. Knox J, Tabrizi SN, Miller P, et al. Evaluation of self-collected samples in contrast to practitioner-collected samples for detection of Chlamydia trachomatis, Neisseria gonorrhoeae, and Trichomonas vaginalis by polymerase chain reaction among women living in remote areas. Sex Transm Dis 2002; 29:647-54.

68. Latiff LA, Ibrahim Z, Pei CP, et al. Comparative assessment of a self-sampling device and gynecologist sampling for cytology and HPV DNA detection in a rural and low resource setting: Malaysian experience. Asian Pac J Cancer Prev 2015 16:8495-501.

69. Cambiano V, Ford D, Mabugu T, et al. Assessment of the potential impact and cost-effectiveness of self-testing for HIV in low-income countries. J Infect Dis 2015; $212: 570-7$.

70. Barnabas RV, van Rooyen H, Tumwesigye E, et al. Uptake of antiretroviral therapy and male circumcision after community-based HIV testing and strategies for linkage to care versus standard clinic referral: a multisite, open-label, randomised controlled trial in South Africa and Uganda. Lancet HIV 2016; 3:e212-20.
71. Wang Z, Lau JTF, Ip M, et al. A randomized controlled trial evaluating efficacy of promoting a home-based HIV self-testing with online counseling on increasing HIV testing among men who have sex with men. AIDS Behav 2018 22:190-201.

72. Zhu X, Zhang W, Operario D, et al. Effects of a mobile health intervention to promote HIV self-testing with MSM in China: a randomized controlled trial. AIDS Behav 2019; 23(11):3129-39.

73. Reddy EA, Agala CB, Maro VP, et al. Test site predicts HIV care linkage and antiretroviral therapy initiation: a prospective 3.5 year cohort study of HIV-positive testers in northern Tanzania. BMC Infect Dis 2016; 16:497.

74. MacGowan RJ, Chavez PR, Borkowf CB, et al. Effect of internet-distributed HIV self-tests on HIV diagnosis and behavioral outcomes in men who have sex with men: a randomized clinical trial. JAMA Intern Med 2019; 180(1):117-25.

75. Landovitz RJ, Tseng CH, Weissman M, et al. Epidemiology, sexual risk behavior and HIV prevention practices of men who have sex with men using GRINDR in Los Angeles, California. J Urban Health 2013; 90:729-39.

76. Marlin RW, Young SD, Bristow CC, et al. Piloting an HIV self-test kit voucher program to raise serostatus awareness of high-risk African Americans, Los Angeles. BMC Public Health 2014; 14:1226.

77. Johnson CC, Kennedy C, Fonner V, et al. Examining the effects of HIV selftesting compared to standard HIV testing services: a systematic review and metaanalysis. J Int AIDS Soc 2017; 20:21594.

78. Neuman M, Taegtmeyer M, Hatzold K, et al. Challenges in measurement of linkage following HIV self-testing: examples from the STAR Project. J Int AIDS Soc 2019; 22(Suppl 1):e25238.

79. Hatcher AM, Turan JM, Leslie HH, et al. Predictors of linkage to care following community-based HIV counseling and testing in rural Kenya. AIDS Behav 2012 16:1295-307.

80. Shamu S, Slabbert J, Guloba G, et al. Linkage to care of HIV positive clients in a community based HIV counselling and testing programme: a success story of non-governmental organisations in a South African district. PLoS One 2019, 14:e0210826.

81. Qvist T, Cowan SA, Graugaard C, Helleberg M. High linkage to care in community-based rapid HIV testing and counseling project among men who have sex with men in Copenhagen. Sex Transm Dis 2014; 41:209-14.

82. Miller RL, Boyer CB, Chiaramonte D, et al. Evaluating testing strategies for identifying youths with HIV infection and linking youths to biomedical and other prevention services. JAMA Pediatr 2017; 171:532-7.

83. Dovel K, Shaba F, Offorjebe OA, et al. Effect of facility-based HIV self-testing on uptake of testing among outpatients in Malawi: a cluster-randomised trial. Lancet Glob Health 2020; 8:e276-87.

84. Morano JP, Zelenev A, Lombard A, Marcus R, Gibson BA, Altice FL. Strategies for hepatitis $\mathrm{C}$ testing and linkage to care for vulnerable populations: point-of-care and standard HCV testing in a mobile medical clinic. J Community Health 2014; 39:922-34.

85. Parker LA, Jobanputra K, Rusike L, et al. Feasibility and effectiveness of two community-based HIV testing models in rural Swaziland. Trop Med Int Health 2015; 20:893-902.

86. Johnston JB, Reimer JN, Wylie JL, Bullard J. Observational study of the populations accessing rapid point-of-care HIV testing in Winnipeg, Manitoba, Canada through a retrospective chart review of site records. Sex Transm Infect 2018 94:194-9. 